\title{
Coronavirus Disease (COVID-19) Pandemic: Common Challenges and Recommendations
}

\author{
Sabah Aziz ${ }^{1}$, Boris Budosan ${ }^{2 *}$ and Aadil Khalil ${ }^{1}$ \\ ${ }^{1}$ Frontier Institute of Medical Sciences, Abbottabad, Pakistan \\ ${ }^{2}$ Mental Health Consultant, Medical School of University of Zagreb, Zagreb, Croatia
}

\begin{abstract}
There are a number of challenges in response to Coronavirus (COVID-19) disease outbreak. The authors discuss common problems related to this outbreak which are encountered by most of the countries in the world. They were divided in those encountered by (health) care delivery systems and those encountered by affected communities and countries. The information presented here was collected from relevant national and global sources. The authors support and recommend practical solutions to overcome difficulties and challenges related to COVID-19 outbreak.
\end{abstract}

Keywords: COVID-19 outbreak, (health) care delivery systems, community and country engagement and preparedness.

\section{INTRODUCTION}

According to the New Humanitarian (formerly IRIN news) [1], global confirmed cases of the coronavirus exceeded 1.48 million by 9 April, including more than 88,000 deaths. More than 180 countries or territories reported infections - including a rising number with weak health systems and large refugee and migrant populations. In spite of all the previous efforts by the World Health Organization (WHO) and other international and national players to strengthen public health systems around the world [2] and improve disaster and epidemic preparedness for future disasters, like e.g. in the Western Pacific after 2013 typhoon Haiyan [3], it seems that the recent COVID-19 outbreak caught everybody by surprise. In our opinion, this happened because most of the previous disaster/epidemic preparedness work has been done only on a policy level but not really tested in practice. Therefore, we recommend more practical disaster/ epidemic preparedness efforts in the future.

Although we have many technical guidelines and documents related to COVID-19 outbreak now [4], the pandemic has not been prevented and the virus has already affected almost entire world and lives of people in many countries. We assume that this outbreak could have been contained better and prevented to spread to the whole world. For example, the outbreak of Ebola in West Africa in 2014 has been mostly contained in Africa with some sporadic cases on other continents. Of course, we understand that COVID-19 is more contagious than Ebola virus, so our assumption may also be wrong. Still, we would recommend more swift

\footnotetext{
*Corresponding Author: Boris Budosan, Mental Health Consultant, Medical School of University of Zagreb, Zagreb, Croatia;

Email:bbudosan@yahoo.com

Received: May 30, 2020; Revised: June 17, 2020; Accepted: June 24, 2020 DOI: https://doi.org/10.37184/lnjpc.2707-3521.1.27
}

action of countries and also international organizations such as the WHO to better contain any eventual outbreaks that may happen in the future.

At this moment we can still see both frontline health and humanitarian workers fighting the outbreak. Countries respond in more or less similar manner following the recommendations of the $\mathrm{WHO}$ and/or their public health authorities. We think that the final outcome of this outbreak will ultimately depend on the effectiveness of public health response of care delivery systems, communities and countries worldwide. It is interesting that some scientists have even already tried to predict the end of the outbreak by the country [5]. Vaccine development has become a global effort [6] and we believe that the vaccine should be distributed globally in the future. One drug called Remdesivir has shown good results in shortening the time to recovery in adults hospitalized with COVID-19 [7]. Some other treatments, like e.g. the use of Chloroquine and Hydroxychloroquine is dubious and can be even harmful, especially in patients with cardiac problems [8]. In Africa, the herbal remedy called Covid-Organics became very popular for prevention and treatment of COVID-19 disease. However, we would recommend only evidence-based treatment for COVID-19.

\section{COMMON CHALLENGES RELATED TO COVID-19 OUTBREAK}

\section{Care Delivery Systems:}

Common challenges encountered by care delivery systems in countries around the world include shortage of personal protective equipment (PPE) to protect health and care workers, insufficient number of health staff and respirators, understaffed public health systems and lack of space in health facilities to accommodate raising number of COVID-19 patients (Table 1). 
Table 1: Common challenges related to COVID-19 outbreak.

Care delivery systems

- Shortage of PPE, health staff, respirators and space for COVID-19 patients.

- Not enough diagnostic testing for COVID-19 and early detection of disease.

- Understaffed public health systems.

Communities

- Challenge of social distancing, isolation and safety nets.

- Shortage of face masks for general population.

- Challenge of tracing contacts and quarantine.

- Mental health, social stigma considerations and domestic violence.

Countries

- Delay in critical preparedness, readiness and response action.

- Economic impact.

- Conflicting messages on COVID-19 outbreak.

- Challenges for humanitarian operations, camps and other fragile settings.

The countries have put in place different measures in order to overcome these challenges. There has been an increase in production of PPE and respirators, e.g. in Europe [9] and increase of donations, for example donation of respirators by China to the USA [10]. UK National Health System (NHS) decided to invite retired health workers to assist with the outbreak in UK [11] and Chinese, Russian and Cuban health staff went to assist the most affected town of Bergamo in Italy [12]. Therefore, we think that in spite of all the difficulties to tackle the outbreak at the beginning, there was a considerable number of good initiatives which showed solidarity within and among different countries. We would definitively recommend that countries and people continue with the show of solidarity in fighting COVID-19 outbreak in future.

Many countries opened additional temporary field hospitals or arranged spaces in different facilities such as churches, mosques and exhibition places to accommodate extra COVID-19 patients and release pressure on health facilities. We think that this was justified especially at the beginning of the outbreak because nobody was sure how many people would be affected by the virus and in need of isolation and/or treatment. Diagnostic testing for COVID-19 is crucial for early detection of disease and tracing contacts in order to isolate them and prevent to spread the disease. This has been for example well done in South Korea, Singapore and Germany. Germany also reported only 0.5-1 \% fatality rate from COVID-19, most probably due to widespread testing [13]. However, most of the countries in the world still lack enough COVID-19 testing kits and are trying to increase their production now. We think that both legislation and action to boost healthcare is needed in many countries at the moment. In our opinion, the outbreak of COVID-19 is providing a good opportunity to apply the principle of "Building back better" to public health systems around the world.

\section{Situation in Pakistan:}

Pakistan has designated 35 hospitals countrywide as COVID-19 designated tertiary hospitals. Similarly, 215 medical facilities with 2942 beds are being used for isolation purpose and there are 139 quarantine facilities throughout the country. Pakistan has also increased the testing capacity to 30,000 per day [14]. Provision of PPE to the frontline workers has also increased but despite all these efforts number of COVID-19 cases has been increasing too.

\section{Communities:}

Social distancing, isolation and safety nets have been challenges for every community, but especially for crowded towns/cities and slums in Africa and Asia where social distancing is virtually impossible and where many daily labourers have to go out and earn their daily wages in order to survive. Many communities in developing countries do not have safety nets other than assistance from their families. Therefore, in many communities volunteers deliver food to elderly, poor and homeless. Shortage of face masks for general population is still a challenge in many communities and their production and donations have increased lately. Longer-term isolation has a negative impact on mental health on many people causing additional stress, anxiety, depression and even domestic violence. Additionally, stigma is attached to people suffering from coronavirus disease, including even health workers who fall ill by helping others. People who die from coronavirus disease in some countries cannot even be buried properly. The best way to overcome these challenges is the education of communities on COVID-19 and mental health assistance to those who suffer from stress and different mental health issues $[15,16]$. Increase in domestic violence should be addressed through timely intervention by local authorities.

\section{Situation in Pakistan:}

Social/physical distancing is a major problem in Pakistan. Rapid increase in number of cases has been reported recently, especially after Pakistani government decided to lift a lockdown [14]. Use of facemasks by general population has increased lately but in general people have not been following the Standard Operating Procedures (SOPs) for prevention of COVID-19 outbreak and bazaars and other shopping places (grocery stores and vegetable 
markets) have often been overcrowded. In Pakistan there are also many misconceptions and myths related to COVID-19. It has often been presented on social media as international propaganda which leads people not to follow SOPs, thereby resulting in increase in number of cases.

\section{Countries:}

Any delay in strategic preparedness and response action for COVID-19 has been a major challenge for every country. Several countries, e.g. China and Singapore have demonstrated that COVID-19 transmission from one person to another can be slowed by social distancing and isolation of suspected and confirmed COVID-19 cases. Unfortunately, in many countries the warning that COVID-19 could become a global epidemic was not taken seriously. For example, the WHO's advice to test and isolate and quarantine suspected cases was not followed even in the UK at the beginning [17].

In response to potential outbreak, many countries worldwide have closed public transportation, places like coffee shops, theatres and religious sites and some even introduced curfews to keep their population out of streets. Many countries also closed their borders to prevent the outbreak and e.g. New Zealand implemented the toughest and most successful border restrictions so far. Social distancing of at least 2 metres became required when going for shopping of necessary food items. "Stay at home" campaigns started to be implemented through printed, audio and visual media. In some countries hotlines have been established for update on COVID-19 outbreak and psychological assistance. However, social distancing and isolation became major challenges for crowded humanitarian settings, such as for example refugee camps which depend on delivery of humanitarian assistance hampered due to COVID-19 outbreak [15].

Economic impact of COVID-19 became a major challenge for every country. In order to overcome economic challenges, many countries offered financial packages and loans for small businesses and humanitarian assistance to vulnerable individuals, e.g. social meals programs and housing for homeless. Countries under economic sanctions e.g. Iran face additional economic difficulties to procure needed PPE, respirators and testing kits [18].

One of the challenges has been related to conflicting messages about COVID-19 by politicians and experts. While politicians in some countries try to underplay the seriousness of the outbreak, experts warn about consequences if proper measures to contain outbreak are not taken. We think that the professional opinion of experts on how to contain the outbreak should precede the statements by politicians which is unfortunately not always the case. However, we also completely understand the concerns of politicians, businesses and ordinary people about slowdown of economy in their countries. Therefore, we would recommend finding a delicate balance between containment of outbreak and restarting economy which must be specific for every country.

\section{Situation in Pakistan:}

A considerable effort has been taken out to combat COVID-19 in Pakistan. Public messages on staying at home and hygiene education through audio and animated video messaging campaigns have continuously been carried out. However, the government decided to lift the imposed lockdown despite rise in number of COVID-19 cases. Businessmen who closed their businesses for more than two months pressurized government to let them open their shops. Government's efforts on giving cash to poor and loans for small businesses are being helpful but cannot be sustained in a longer run. We understand that it is difficult for a poor country like Pakistan to continue lockdown as there are not enough resources to feed millions of poor for a long time. In our opinion, the struggle between imposing lockdown and opening up businesses will continue in Pakistan in a near future.

\section{CONFLICT OF INTEREST}

The authors declare no conflict of interest.

\section{ACKNOWLEDGEMENTS}

We would like to acknowledge the inspiring work of all brave health and humanitarian workers around the world who risk their lives to assist population affected by COVID-19 virus outbreak

\section{REFERENCES}

1. The New Humanitarian. Mapped: Where the Corona virus is spreading. Available at: http://www.thenewhumanitarian.org (Accessed on: April 09, 2020).

2. World Health Organization. Strengthening health systems to improve health outcomes. WHO's Framework for Action. Available at: http://www.who.int/healthsystems/strategy/everybodys_ business.pdf. (Accessed on: April 08, 2020)

3. World Health Organization - Western Pacific Region. Western pacific regional framework for action for disaster risk management and health. Available at: http://www.wpro.who.int/publications/en/ (Accessed on: April 08, 2020).

4. World Health Organization. Country \& Technical Guidance Coronavirus disease (COVID-19). Available at:

https://www.who.int/emergencies/diseases/novel-coronavirus2019/technical-guidance (Accessed on: April 08, 2020). 
5. Luo J. When will COVID-19 end? Data-Driven Prediction. Singapore University of Technology and Design: 2020. Available at:https://www.in.gr/wp-content/uploads/2020/05/covid19 predictionpaper.pdf (Accessed on: May 15, 20).

6. Mullard A. COVID-19 vaccine development pipeline gears up. Lancet 2020; 395: 1751-2.

7. Beigel HJ, Tomashek MK, Dodd LE, Mehta AK, Zingman BS, Kalil $\mathrm{AC}$, et al. Remdesivir for the treatment of Covid-19 - preliminary report. N Engl J Med Available 2020; [Online ahead of print].

8. Funck-Bertrano C, Salem J-E. 2020. Chloroquine or hydroxychloroquine for COVID-19: why might they be hazardous? The Lancet 202; S0140-6736(20): 31174-0.

9. European Commission. Ensuring the availability of supply and equipment. Available at: https://ec.europa.eu/info/live-worktravel-eu/health/coronavirus-response/public-health en (Accessed on: April 10, 2020).

10. CNBC. China is donating 1,000 ventilators to help New York in coronavirus fight. Available at: https://www.cnbc.com/2020/04/ 04/china-is-donating-1000-ventilators-to-help-new-york-incoronavirus-fight.html (Accessed on: April 10, 2020).

11. Personnel Today. NHS invited retired doctors and nurses to return. Available at: https://www.personneltoday.com/hr/nhs-returners-coronavirus/ (Accessed on: April 10, 2020).

12. National Public Radio (NPR). For help on corona virus, Italy turns to China, Russia and Cuba.

Available at: https://www.npr.org/sections/coronavirus-live-up- dates $/ 2020 / 03 / 25 / 821345465 /$ for-help-on-coronavirusitaly-turns-to-china-russia-and-cuba?t=1586531535832

(Accessed on: April 10, 2020).

13. BBC. Coronavirus: why death and mortality rates differ. Available at: https://www.bbc.com/future/article/20200401-coronaviruswhy-death-and-mortality-rates-differ (Accessed on: April 11, 2020).

14. Government of Pakistan. Coronavirus in Pakistan. Available at: http://covid.gov.pk/ (Accessed on: May 29, 2020).

15. The New Humanitarian. Coronavirus and aid: what we are watching.

Available at: https://www.thenewhumanitarian.org/news/2020/ 04/09/coronavirus-humanitarian-aid-response?utm_source= The+New+Humanitarian\&utm_campaign $=7 \mathrm{fa} 315 \mathrm{ffc} 2$-EMAIL CAMPAIGN_04_9_2020_DAILY\&utm_medium = email\&utm term $=0$ d8 842 d98289-7 fa315ffc2-75430337

(Accessed on: April 10, 2020).

16. WHO. Mental health and psychosocial considerations during COVID-19 outbreak. WHO, Geneva. Available at: https://www.who.int/publications-detail/mental-health-andpsychosocial-considerations-during-the-covid-19-outbreak (Accessed on: April 11, 2020).

17. Richard H. Offline: COVID-19 and the NHS-"a national scandal". The Lancet 2020; 395: 1022.

18. Murphy A, Abdi Z, Harirchi I, McKee M, Ahmadnezhad E. Economic sanctions and Iran's capacity to respond to COVID-19. Lancet Public Health 2020; 5: e254. 